\title{
Penguatan Jejaring Bisnis melalui Kualitas Layanan di PP Properti
}

\author{
Leonnard Ong \\ Sekolah Tinggi Manajemen IPMI, DKI Jakarta12750, Indonesia \\ Author E-mail: Leonnard.ong@ipmi.ac.id
}

\begin{abstract}
A B S T R A K
Dalam industri konstruksi, hubungan antara pelanggan dan kontraktor merupakan suatu hubungan yang kompleks dan bertingkat antara para pihak secara bersamaan dan berkolaborasi dalam suatu jaringan. Pelanggan dalam industri konstruksi merupakan suatu kesatuan dalam jaringan bisnis yang dibangun dan dikembangkan sehingga perusahaan konstruksi menjadi tumbuh dan berkembang. Salah satu perusahaan yang bergerak dalam industri konstruksi dan properti di Indonesia adalah PT PP Properti. Pemahaman terkait dengan dimensi service quality pada perusahaan konstruksi, khususnya di PT PP Properti perlu ditingkatkan agar tindakan dari seluruh organisasi mampu memberikan layanan yang terbaik kepada para pelanggannya, baik pelanggan internal maupun eksternal. Dalam reviu literatur yang telah dilakukan, service quality dalam disiplin konstruksi telah diteliti oleh banyak pakar. Service Quality adalah alat bantu yang dapat digunakankan untuk proses mendapatkan network business, menciptakan dan mempertahankan partnership. Dalam upaya penguatan jejaring bisnis PP Properti, dimensi kehandalan (reliability), daya tanggap (responsiveness), jaminan (assurance), dan bukti langsung/berwujud (tangibles) merupakan hal yang penting dalam industri konstruksi. Lebih lanjut, diperlukan penelitian survei untuk mengevaluasi dan mengukur kualitas pelanggan setelah penerapan service quality di PP Properti.
\end{abstract}

Kata Kunci: Jejaring Bisnis, Pelanggan, Kualitas, Service Quality.

\section{A B S T R A C T}

In the construction industry, the relationship between customers and contractors is a complex and multilevel relationship between the parties together and collaborating in a network. Customers in the construction industry are an integral part of a business network that is built and developed so that construction companies grow and develop. One of the companies engaged in the construction and property industry in Indonesia is PT PP Properti. Understanding related to the dimensions of service quality in construction companies, especially at PT PP Properti, needs to be improved so that the actions of the entire organization are able to provide the best service to its customers, both internal and external customers. In the literature review that has been carried out, service quality in the construction discipline has been researched by many experts. Service Quality is a tool that can be used in the process of getting a network business, creating and maintaining partnerships. In an effort to strengthen the PP Properti business network, the dimensions of reliability, responsiveness, assurance, and tangibles are important in 
the construction industry. Furthermore, survey research is needed to evaluate and measure customer quality after the implementation of service quality at PP Properti.

Key word: Business Network, Customers, Quality, Service Quality.

Copyright $(2021$ Authors. This is an open access article distributed under the Creative Commons Attribution License, which permits unrestricted use, distribution, and reproduction in any medium, provided the original work is properly cited.

\section{PENDAHULUAN}

Persaingan dalam era globalisasi dan informasi baik bagi perusahaan nasional maupun internasional sudah dipastikan sangat ketat. Perusahaan yang ingin berkembang atau tetap berada dan diakui di pasarnya harus dapat memberikan pelayanan yang terbaik bagi konsumen atau pelanggannya melalui kualitas barang dan jasa yang diberikan.

Pelanggan (customer) adalah siapa saja yang menerima layanan perusahaan, termasuk pelanggan eksternal di luar organisasi misalnya pelanggan bisnis, pemasok, sejawat bisnis, ataupun konsumen akhir dari produk, maupun pelanggan internal misalnya karyawan departemen lain, atau karyawan sejawat lainnya. Persepsi kualitas dari pelanggan akan berpengaruh terhadap kepuasan pelanggan dan selanjutnya akan dapat berpengaruh pula pada loyalitas pelanggan (Heskett et al, 1997). Selain itu, kepuasan pelanggan juga akan berpengaruh positif pada komunikasi word of mouth, peningkatan pendapatan, maupun tingkat pengembalian pada pemegang saham.

Persepsi kualitas merupakan hasil evaluasi yang dirasakan oleh pelanggan secara komprehensif atas barang atau jasa yang telah diperoleh (Zeithaml, 1988). Penilaian service quality meliputi kualitas keluaran, kualitas interaksi, maupun kualitas lingkungan fisik. Oleh karena itu, 5 dimensi service quality, yaitu reliability, assurance, tangibles, empathy, dan responsiveness. Atributatribut tersebut akan mempengaruhi bagaimana hasil evaluasi layanan yang dipersepsikan oleh pelanggan.

Secara spesifik, dalam industri konstruksi, hubungan antara pelanggan dan kontraktor merupakan suatu hubungan yang kompleks dan bertingkat antara para pihak secara bersamaan dan berkolaborasi dalam suatu jaringan (Omonori dan Lawal, 2014). Oleh karena itu, kepuasan pelanggan dalam perusahaan konstruksi dihasilkan dari hubungan yang spesifik. Berbeda dengan bidang produksi lainnya, dimana hubungan antar klien dan pemasok sering kali bersifat jangka panjang, hubungan dalam konstruksi bersifat berkala dan bergantung pada lamanya proyek. Secara umum, konstruksi tidak berbagi manfaat dari kegiatan jalur reguler. Selain itu, kerjasama timbal balik antara pelanggan dan kontraktor sangat erat. Sifat kompleks dari proses konstruksi, perubahan dalam organisasi proyek, dan keunikan setiap proyek membuatnya sulit untuk memanfaatkan pengalaman masa lalu dan umpan balik pelanggan di masa depan. Pelanggan dalam industri konstruksi merupakan suatu kesatuan dalam jaringan bisnis yang dibangun dan dikembangkan sehingga perusahaan konstruksi menjadi tumbuh dan berkembang.

Salah satu perusahaan yang bergerak dalam industri konstruksi dan properti di Indonesia adalah PT PP Properti. PT PP Properti memiki jaringan usaha yang luas, diantaranya 6 Hotel, 11 Pusat Perbelanjaan, dan 33 Apartemen (PP Properti, 2020). Perusahaan melakukan investasi pada berbagai entitas anak dan entitas asosiasi yang berperan sebagai kontraktor dan / atau operator atau pengelola realti maupun properti. Per 31 Desember 2019, Perusahaan memiliki 9 (sembilan) entitas anak, 8 (delapan) entitas asosiasi, 5 (lima) penyertaan saham, serta 2 (dua) Kerja Sama Operasi (KSO), sebagai jaringan usaha PP Properti dengan sebaran pasar mencakup 
Jakarta dan Jawa Barat serta daerah di luar kedua area tersebut.

Pemahaman terkait dengan dimensi service quality pada perusahaan konstruksi, khususnya di PT PP Properti perlu dipahami agar tindakan dari seluruh organisasi mampu memberikan layanan yang terbaik kepada para pelanggannya, baik pelanggan internal maupun eksternal. Hal tersebut merupakan hal yang kritis dalam menentukan kepuasan dan loyalitas. Kepuasan dan loyalitas tersebut akan memperluas dan menajamkan jaringan pelanggan baik eksternal maupun internal organisasi. Pemahaman terkait hal-hal yang bersifat kritis bagi organisasi sangat diperlukan. Pemahaman terkait teori kualitas layanan yang diperoleh melalui riset pengajar perlu untuk diteruskan dan didiskusikan secara implementatif dalam organisasi / perusahaan. Pengabdian pengajar kepada masyarakat dapat dilakukan melalui penyuluhan dan diskusi terbuka dengan perusahaan, khususnya dengan tema penguatan jejaring bisnis melalui service quality.

\section{Kajian Teori}

\section{Customer Perceptions}

Persepsi pelanggan terhadap kualitas didasarkan atas 5 atribut, yaitu reliability, assurance, tangibles, empathy, dan responsiveness. Atributatribut tersebut akan mempengaruhi bagaimana hasil evaluasi layanan yang dipersepsikan oleh pelanggan. Bersama dengan kualitas produk/ barang dan harga yang harus dibayarkan oleh pelanggan, akan membentuk kepuasan pelanggan.

Walaupun demikian, kepuasan pelanggan tergantung pula pada faktor situasional dan personal. Persepsi kualitas dari pelanggan akan berpengaruh terhadap kepuasan pelanggan dan selanjutnya akan dapat berpengaruh pula pada loyalitas pelanggan (Heskett et al, 1997).

\section{Customer Satisfaction}

Kepuasan pelanggan merupakan evaluasi spesifik terhadap keseluruhan pelayanan yang diberikan pemberi jasa, sehingga kepuasan pelanggan hanya dapat dinilai berdasarkan pengalaman yang pernah dialami saat proses pemberian pelayanan. Menurut Kotler (2003) kepuasan merupakan perasaan senang ataupun kecewa seseorang yang berasal dari perbandingan antara kesannya terhadap kinerja (atau hasil) suatu produk dan harapan-harapannya. Selain itu juga definisinya berdasarkan disconfirmation paradigm (Oliver, 1997), bahwa kepuasan pelanggan dirumuskan sebagai evaluasi pascabeli. Apabila persepsi terhadap kinerja tidak bisa memenuhi harapan, maka akan terjadi ketidakpuasan.

Kepuasan biasanya merupakan evaluasi komprehensif terhadap konsumsi barang dan jasa (Li dan Petrick, 2010; Gallarza et al., 2011) atau merupakan respon emosional atas pengalaman interaksi dengan sebuah institusi/ entitas (Boulding et al, 1993). Kepuasan pelanggan telah menjadi konsep sentral dalam teori dan praktek pemasaran, serta merupakan faktor yang esensial bagi kegiatan bisnis.

Apabila kinerja melebihi harapan, konsumen akan merasakan sangat puas. Ketika konsumen merasakan ketidakpuasan, konsumen akan enggan untuk menggunakan lagi jasa perusahaan tadi. Mereka akan cenderung untuk mencari perusahaan lain yang mereka anggap akan menawarkan tingkat kepuasan yang mereka harapkan. Atau dengan kata lain jika tingkat kepuasan yang dirasakan rendah, maka akan mempengaruhi niat untuk berpindah.

Persepsi kualitas dari pelanggan akan berpengaruh terhadap kepuasan pelanggan dan selanjutnya akan dapat berpengaruh pula pada loyalitas pelanggan (Heskett et al, 1997). Selain itu, kepuasan pelanggan juga akan berpengaruh positif pada komunikasi word of mouth, peningkatan pendapatan, maupun tingkat pengembalian pada pemegang saham.

\section{Service Quality}

Persepsi kualitas merupakan hasil evaluasi yang dirasakan oleh pelanggan secara komprehensif atas barang atau jasa yang telah diperoleh (Zeithaml, 1988). Berdasarkan Grönroos (1984), terdapat 2 indikator yang digunkan untuk 
mengevaluasi service quality, yaitu kualitas teknis dan kualitas fungsional. Kualitas teknis merupakan kualitas fisik yang berkaitan dengan layanan yang diberikan sedangkan kualitas fungsional merupakan kualitas pemberian layanan itu sendiri (Rust dan Oliver, 1993).

Penilaian service quality (SERVQUAL) meliputi kualitas keluaran, kualitas interaksi, maupun kualitas lingkungan fisik. Skala SERVQUAL yang dikemukakan oleh Parasuraman, Zeithaml, dan Berry dalam serangkaian penelitian terhadap enam perusahaan jasa $(1985,1988,1991,1994)$ menunjukkan bahwa perbedaan antara harapan konsumen mengenai kinerja dari perusahaan dan penilaian konsumen mengenai kinerja aktual memberikan suatu persepsi konsumen atas kualitas jasa. Dalam konteks pengukuran variabel kualitas pelayanan, Parasuraman, et al (1988) mengidentifikasikan lima dimensi ukuran kualitas layanan yaitu reliability (keandalan), responsiveness (daya tanggap), assurance (jaminan), tangibles (bukti langsung), dan empathy (empati). Pengukuran semacam ini dikenal sebagai model service quality (SERVQUAL).

Lima dimensi service quality (SERVQUAL) yaitu:

1. Keandalan (reliability); yakni kemampuan memberikan pelayanan yang dijanjikan dengan segera, akurat, dan memuaskan.

2. Jaminan (assurance); mencakup pengetahuan, kemampuan, kesopanan, dan sifat dapat dipercaya yang dimiliki para staf, bebas dari bahaya, risiko, atau keraguraguan.

3. Bukti langsung (tangibles); meliputi fasilitas fisik, perlengkapan, pegawai, dan sarana komunikasi.

4. Empati (empathy); meliputi kemudahan dalam melakukan hubungan, komunikasi yang baik, perhatian pribadi, dan memahami kebutuhan para pelanggan.

5. Daya tanggap (responsiveness); yaitu keinginan para staf untuk membantu para pelanggan dan memberikan pelayanan dengan tanggap.

Dabhokar, et al. (1996) mengajukan dimensi ukuran kualitas jasa pada bisnis ritel yang meliputi physical aspects, reliability, personal interaction, problem solving dan policy yang merupakan kombinasi dari literatur ritel dan SERVQUAL. Atribut-atribut tersebut akan mempengaruhi bagaimana hasil evaluasi layanan yang dipersepsikan oleh pelanggan. Sebagai contoh diskusi dalam institusi pendidikan, kepuasan mahasiswa menjadi perhatian khusus. Di antara banyak faktor yang berpengaruh positif terhadap kepuasan siswa, kualitas layanan telah dianggap sebagai faktor kunci (Leonnard et al, 2015; Leonnard \& Susanti, 2019; Leonnard, 2018a; Leonnard, 2018b). Lebih lanjut, Leonnard (2018b) juga menemukan bahwa kepuasan siswa di perguruan tinggi swasta secara umum bergantung pada kualitas faktor-faktor berwujud (tangible) dan kehandalan (reliability) seperti kenyamanan ruang pengajar, fasilitas perpustakaan yang memadai, kerapihan tampilan staf kependidikan, perlakuan non-diskriminatif yang disediakan oleh staf dan pengajar, kemampuan dan pengetahuan yang memadai oleh staf dan pengajar, serta layanan akademik yang memadai disediakan oleh universitas.

Selain hubungan positif dengan kepuasan, kualitas layanan yang tinggi juga akan menimbulkan loyalitas yang salah satunya melalui Word of Mouth (WOM) (Leonnard et al., 2013; Leonnard et al, 2015). Hubungan positif ini dibuktikan pada studi sebelumnya tentang pelayanan transportasi umum (Leonnard dan Susilowati, 2018).

\section{METODOLOGI}

Studi ini melalui pendekatan studi literatur dan proses diskusi dan penyuluhan dengan sasaran staf dan manajemen PP Properti yang dihadiri oleh 14 peserta dan merupakan pengelola bisnis PP Properti untuk bisnis retail, whole sales dari proses hulu ke hilir. Penyuluhan ini penting untuk membantu para peserta yang berasal dari staf dan manajemen PP Properti dalam memahami beberapa dasar konseptual persepsi konsumen dan service quality. Pada umumnya penyuluhan yang diberikan dapat memberikan dorongan dan ide untuk aplikasi praktis atribut service quality di lingkungan kerja masing-masing. 
Kegiatan penyuluhan dilakukan secara live virtual tentang "Building Strong Network through Service Quality" pada tanggal 26 Februari 2021 dengan Meeting ID: 94865305018 dan Passcode: 483923. Metode yang dilakukan adalah seperti berikut: 1. Para peserta diberikan penyuluhan yang diisi dengan materi terkait persepsi pelanggan, dan persepsi atas kualitas dan pengaruhnya terhadap kepuasan dan loyalitas. Para peserta juga dibimbing dalam memahami konsep dan aplikasi service quality dan 5 atributnya pada industri yang berbeda-beda.

2. Mengadakan sesi tanya jawab dan latihan yang diharapkan menjawab masalah praktis yang dihadapi maupun konsep.

Studi ini juga menggunakan pendekatan studi literatur dan menghubungkan dengan yang dilakukan oleh PT PP Properti. Literatur yang direviu terkait dengan kualitas dan service quality yang dilakukan pada industri konstruksi.

\section{DISKUSI DAN PEMBAHASAN}

Definisi kualitas dalam industri konstruksi cukup beragam. Loushine et al (2006), dalam tinjauan literaturnya tentang manajemen mutu dan keselamatan di industri konstruksi, mencatat definisi kinerja kualitas yang beragam, mulai dari "memenuhi harapan pelanggan", "mengurangi pengerjaan ulang atau cacat", "mengulang bisnis", "kesesuaian dengan kriteria ISO 9000", dan "penyelesaian tepat waktu dan sesuai anggaran". Kualitas merupakan salah satu faktor penentu keberhasilan proyek konstruksi. Kualitas proyek konstruksi, seperti serta keberhasilan proyek, dapat dianggap sebagai pemenuhan harapan (yaitu kepuasan) pengguna proyek (Ashokkumar , 2014).

Oleh karena itu, Hoonaker et al (2010) menyampaikan bahwa cara terbaik untuk meningkatkan kualitas adalah melalui pendidikan dan pelatihan personel karena penghalang terbesar untuk kualitas adalah keterbatasan personel. Selain itu, beberapa hal yang mempengaruhi kualitas konstruksi, diantaranya keterbatasan pendanaan, keterbatasan komunikasi, keterbatasan tenaga kerja dan upahnya, keterbatasan detil perencanaan gedung dan konstruksi, keterbatasan material dan perlengkapan, keterbatasan waktu, keterbatasan metode konstruksi, keterbatasan aturan dan regulasi, kebijakan pelatihan, dan keterbatasan koordinasi antar departemen (Ashokkumar, 2014).

Hoonaker et al (2010) mengevaluasi bahwa kualitas konstruksi paling sering diukur melalui kepuasan pelanggan. Dalam konstruksi, kepuasan pelanggan dapat ditentukan oleh sejauh mana fasilitas fisik (produk) dan proses konstruksi (layanan) memenuhi dan/atau melebihi harapan pelanggan (Omonori dan Lawal, 2014). Definisi ini menjustifikasi pentingnya memahami, mengevaluasi, mendefinisikan, dan mengelola ekspektasi sehingga persyaratan pelanggan terpenuhi.

Oleh karena pertumbuhan dan perkembangan industri konstruksi sangat bergantung pada kepuasan pelanggan, pertumbuhan industri konstruksi hanya bisa dicapai jika calon pelanggan atau klien tertarik dengan investasi peluang di industri konstruksi tersebut. Menurut Omonori dan Lawal (2014), kepuasan pelanggan dapat diukur dengan beberapa cara, diantaranya rating kualitas, rating jadwal penyelesaian, dan rating harga.

Salah satu perusahaan yang bergerak dalam industri konstruksi dan properti di Indonesia adalah PT PP Properti. Berdasarkan Laporan Tahunan PT PP Properti, Tbk tahun 2019 (PP Properti, 2020), perusahaan memiliki 3 (tiga) unit bisnis, yaitu Komersial, Residensial dan Hospitality. Oleh karenanya, PP Properti memiliki target konsumen yang bervariasi, mulai dari masyarakat yang berpenghasilan rendah hingga kelas atas, yang disesuaikan dengan masingmasing properti yang sedang dikembangkan, baik yang pada level retail sales dan whole sales, untuk proyek proyek apartemen strata (i.e. jual putus) dan recurring income (i.e. sewa) seperti hotel dan mall. Proyek-proyek yang telah dijalankan maupun sedang dikembangkan oleh Perusahaan sebagian besar terletak di Jakarta 
dan Jawa Barat. Namun demikian, PP Properti juga memiliki proyek baik properti maupun realti yang tersebar di berbagai wilayah Indonesia.

Dalam hal meningkatkan kualitas pelayanan kepada pelanggan, beberapa hal telah dilakukan oleh PP Properti di tahun 2019 (PP Properti, 2020), diantaranya:

1. Memastikan bahwa kualitas produk dan layanan yang diberikan Perusahaan adalah sama dengan spesifikasi yang disampaikan kepada publik.

2. Meningkatkan standar pelayanan minimal dalam rangka meningkatkan pelayanan kepada pelanggan.

3. Memberikan kemudahan pengaduan bagi para pelanggan yang dituangkan dalam kegiatan direct mailing, web portal, dan costumer visit.

4. Membuat survei kepuasan pelanggan setiap tahun guna memperbaiki kualitas atas produk dan layanan yang diberikan Perusahaan.

Salah satu implikasi yang dihasilkan atas program peningkatan kualitas pada pelanggan, PP Properti telah menguasai pangsa pasar properti BUMN lebih kurang 35\%. Perusahaan memiliki pangsa pasar yang cukup signifikan, lebih kurang 10\% di wilayah Jabodetabek untuk apartemen terjangkau, sementara di segmen yang sama di kota Surabaya dan kota Semarang, perusahaan menguasai pangsa pasar antara $20 \%$ hingga 30\% (PP Properti, 2020).

Persepsi kualitas dari pelanggan akan berpengaruh terhadap kepuasan pelanggan dan selanjutnya akan dapat berpengaruh pula pada loyalitas pelanggan (Heskett et al, 1997). Pemahaman terkait dengan dimensi service quality pada perusahaan konstruksi, khususnya di PT PP Properti perlu dipahami agar tindakan dari seluruh organisasi mampu memberikan layanan yang terbaik kepada para pelanggannya, baik pelanggan internal maupun eksternal. Hal tersebut merupakan hal yang kritis dalam menentukan kepuasan dan loyalitas. Kepuasan dan loyalitas tersebut akan memperluas dan menajamkan jaringan pelanggan baik eksternal maupun internal organisasi.

Dalam reviu literatur yang telah dilakukan, service quality dalam disiplin konstruksi telah diteliti oleh banyak pakar, diantaranya oleh Samson dan Parker (1994) yang memanfaatkan SERVQUAL dalam industri teknik konsultasi, Nelson dan Nelson (1995) membuat RESERV, yang merupakan versi modifikasi dengan menambahkan dua dimensi terkait dengan pialang real estat, dan Hoxley (1994) mengembangkan SURVEYQUAL untuk perusahaan survei bangunan, yang kemudian diterapkan pada profesional konstruksi (Hoxley, 2000). Siu et al (2001) dan Lai dan Pang (2010) juga mengembangkan versi modifikasinya untuk menilai jasa perawatan gedung. Holm (2000a; 2000b) mempelajari persepsi kualitas pelayanan penghuni apartemen terhadap jasa pemugaran dan asosiasi perumahan di Swedia.

Selain itu, dalam sektor konstruksi perumahan, Sunindijo et al (2014) mengembangkan versi SERVQUAL empat dimensi untuk menilai hubungan antara persepsi kualitas layanan dan niat perilaku pelanggan dalam hubungan bisnis yang sedang berlangsung dengan kontraktor perumahan Thailand. Beberapa temuan penting dalam penelitian yaitu pertama, untuk memberikan kualitas layanan yang baik bagi klien di proyek konstruksi kecil dan menengah di Thailand, kontraktor harus fokus pada dimensi kualitas layanan, yang terdiri dari kehandalan (reliability), daya tanggap (responsiveness), jaminan (assurance), dan bukti langsung / berwujud (tangibles). Kedua, di dalam konteks yang sama, penelitian telah menemukan bahwa kepuasan klien merupakan mediator dari hubungan kausal antara kualitas layanan dan behavioural intention (keinginan untuk membeli dan menawarkan kembali). Ketiga, meskipun kualitas layanan penting untuk memastikan kepuasan klien yang mengarah pada behavioural intention, kontraktor harus fokus pada menjaga kepuasan klien setelah proyek selesai sehingga tetap mendorong behavioural intention. 
Forsythe (2015) juga memodifikasi SERVQUAL dan menggunakannya untuk mengevaluasi kualitas konstruksi pada saat proses konstruksi dilakukan. Studi ini melihat secara rinci tentang insiden yang terjadi selama konstruksi dan pembentukan kualitas layanan yang dipersepsikan pelanggan, termasuk bagaimana persepsi tersebut berdampak evaluasi kepuasan pelanggan konstruksi perumahan di Australia.

PP Properti mengembangkan beberapa proyek termasuk proyek internal maupun melalui joint venture dengan pihak ketiga, baik dengan swasta maupun dengan Badan Usaha Milik Negara (BUMN) untuk mencipatakan bisnis pengembangan properti seperti apartemen, hotel, perkantoran, mall, pusat perdagangan dan perumahan yang dijual dan disewakan. PP Properti saat ini fokus terhadap pengembangan hunian bertingkat di segmen menengah, meningkatkan pendapatan berulang (recurring income) dan peningkatan lahan baru di berbagai daerah strategis di dalam kota (PP Properti, 2020).

Service Quality adalah alat bantu yang dapat digunakankan untuk proses mendapatkan network business, menciptakan dan mempertahankan partnership. Pelanggan PP Properti dalam semua segmen tersebut secara teori tidak mengetahui konsep service quality, namun pelanggan akan merasakan kualitas layanan yang diberikan melalui staf dan tim yang menjalankan program peningkatan kualitas dengan menggunakan pendekatan service quality yang tepat. Dalam memenuhi persepsi kualitas pelanggan, PP Properti perlu menggunakan 2 indikator utama yaitu kualitas teknis dan kualitas fungsional (Grönroos, 1984) atas konstruksi atau bangunan yang dihasilkan, dimana kualitas teknis merupakan kualitas fisik yang berkaitan dengan layanan yang diberikan sedangkan kualitas fungsional merupakan kualitas pemberian layanan itu sendiri (Rust dan Oliver, 1993).

Seperti halnya yang ditemukan oleh Sunindijo et al (2014), dimensi kehandalan (reliability), daya tanggap (responsiveness), jaminan (assurance), dan bukti langsung/berwujud (tangibles) merupakan hal yang penting dalam industri konstruksi, demikan pula halnya dengan PP Properti. Sebagai contoh, reliability akan terkait dengan janji promosi untuk pembangunan tepat waktu dan tepat anggaran, sedangkan assurance akan terkait dengan proses legal pengadaan lahan dan sertifikasi lahan yang diperoleh oleh pelanggan atas bangunan yang dijanjikan. Dimensi responsiveness diwujudkan melalui kemudahan pengaduan bagi para pelanggan yang dituangkan dalam kegiatan direct mailing, web portal, dan costumer visit, serta adanya survei kepuasan pelanggan yang dilaksanakan setiap tahun. Namun, keduanya harus disertai dengan tanggapan dan tindak lanjut yang tepat dan segera. Sementara itu, dimensi bukti langsung/berwujud (tangibles) diaplikasikan melalui ketepatan spesifikasi dan disain yang dijanjikan sesuai dengan standar pelayanan minimal yang ditetapkan.

\section{KESIMPULAN DAN REKOMENDASI}

Salah satu perusahaan yang bergerak dalam industri konstruksi dan properti di Indonesia adalah PT PP Properti. PT PP Properti memiki jaringan usaha yang luas, diantaranya 6 Hotel, 11 Pusat Perbelanjaan, dan 33 Apartemen (PP Properti, 2020). perusahaan memiliki 3 (tiga) unit bisnis, yaitu Komersial, Residensial dan Hospitality. Oleh karenanya, PP Properti memiliki target konsumen yang bervariasi, mulai dari masyarakat yang berpenghasilan rendah hingga kelas atas, yang disesuaikan dengan masingmasing properti yang sedang dikembangkan, baik yang pada level retail sales dan whole sales, untuk proyek proyek apartemen strata (i.e. jual putus) dan recurring income (i.e. sewa) seperti hotel dan mall.

Pemahaman terkait dengan dimensi service quality pada perusahaan konstruksi, khususnya di PT PP Properti perlu ditingkatkan agar tindakan dari seluruh organisasi mampu memberikan layanan yang terbaik kepada para pelanggannya, baik pelanggan internal maupun eksternal. Dalam reviu literatur yang telah dilakukan, service quality dalam disiplin konstruksi telah diteliti 
oleh banyak pakar, diantaranya oleh Samson dan Parker (1994), Nelson dan Nelson (1995), Hoxley, 2000, Siu et al (2001), Lai dan Pang (2010), Holm (2000a; 2000b), Sunindijo et al (2014), dan Forsythe (2015).

Service Quality adalah alat bantu yang dapat digunakan untuk proses mendapatkan network business, menciptakan dan mempertahankan partnership. Dalam memenuhi persepsi kualitas pelanggan, PP Properti perlu menggunakan 2 indikator utama yaitu kualitas teknis dan kualitas fungsional (Grönroos, 1984) atas konstruksi atau bangunan yang dihasilkan, dimana kualitas teknis merupakan kualitas fisik yang berkaitan dengan layanan yang diberikan sedangkan kualitas fungsional merupakan kualitas pemberian layanan itu sendiri (Rust dan Oliver, 1993). Dalam upaya penguatan jejaring bisnis PP Properti, dimensi kehandalan (reliability), daya tanggap (responsiveness), jaminan (assurance), dan bukti langsung / berwujud (tangibles) merupakan hal yang penting dalam industri konstruksi (Sunindijo et al, 2014).

Upaya-upaya yang perlu dilakukan oleh PP Properti disarankan mengarah ke dalam dimensidimensi tersebut. Sebagai contoh, reliability akan terkait dengan janji promosi untuk pembangunan tepat waktu dan tepat anggaran, sedangkan assurance akan terkait dengan proses legal pengadaan lahan dan sertifikasi lahan yang diperoleh oleh pelanggan atas bangunan yang dijanjikan. Dimensi responsiveness diwujudkan melalui kemudahan pengaduan bagi para pelanggan yang dituangkan dalam kegiatan direct mailing, web portal, dan costumer visit, serta adanya survei kepuasan pelanggan yang dilaksanakan setiap tahun. Namun, keduanya harus disertai dengan tanggapan dan tindak lanjut yang tepat dan segera. Sementara itu, dimensi bukti langsung/berwujud (tangibles) diaplikasikan melalui ketepatan spesifikasi dan disain yang dijanjikan sesuai dengan standar pelayanan minimal yang ditetapkan.

Atribut-atribut tersebut akan mempengaruhi bagaimana hasil evaluasi layanan yang dipersepsikan oleh pelanggan. Pelanggan dalam industri konstruksi merupakan suatu kesatuan dalam jaringan bisnis yang dibangun dan dikembangkan sehingga perusahaan konstruksi menjadi tumbuh dan berkembang. Dalam industri konstruksi, hubungan antara pelanggan dan kontraktor merupakan suatu hubungan yang kompleks dan bertingkat antara para pihak secara bersamaan dan berkolaborasi dalam suatu jaringan (Omonori dan Lawal, 2014). Oleh karena itu, jika persepsi kualitas layanan di PP Properti tinggi baik pada segmen masyarakat berpenghasilan rendah hingga atas, maka jaringan bisnis dan usaha diharapkan juga akan menguat. Jaringan hotel, pusat perbelanjaan, dan apartemen yang dimiliki perusahaan saat ini akan menguat dan hal tersebut bisa jadi menguatkan dan mengembangkan unit-unit bisnis yang saat ini ada di PP Properti.

Namun, dalam studi pengabdian masyarakat ini, hanya dilakukan melalui reviu atas beberapa literatur terkait service quality yang diharapkan dapat menjadi alat bantu penguatan network dan partnership bagi bisnis PP Properti. Selanjutnya, implementasi atas konsep service quality yang dijabarkan dan diperkenalkan kepada staf dan manajemen PP Properti tersebut dapat dilakukan. Ke depan, penelitian praktis untuk mengevaluasi dan mengukur kualitas pelanggan setelah penerapan service quality perlu dilakukan menggunakan penelitian survei yang lebih komprehensif, sehingga dapat diketahui secara empirik terkait hubungan peningkatan kualitas layanan dan penguatan jaringan bisnis di PP Properti. 


\section{DAFTAR PUSTAKA}

Ashokkumar, D. (2014). Study of Quality Management in Construction Industry. International Journal of Innovative Research in Science, Engineering and Technology, Volume 3, Special Issue 1.

Boulding, W, Kalra A, Staelin R, Zeithaml VA. (1993). A dynamic process model of service quality: From expectation to behavioral intentions. Journal of marketing research. Vol .30, pp. 7-27.

Dabhokar, and J.O Rentz. (1996). A Measure of Service Quality for Retail Stores: Scale Development and Validation. Journal of The Academy of Marketing Science, Vol 24 No. 1 pp 3 - 16.

Forsythe, P., (2015). Monitoring Customer Perceived Service Quality and Satisfaction during the Construction Process. Construction Economics and Building, 15(1), 19-42.

Gallarza, MG, Gil-Saura I, Holbrook MB. (2011). The value of value: Further excursions on the meadning and role of customer value. Journal of consumer behaviour. Vol. 10(4), pp 179-191.

Grönroos, C. 1984. A service quality model and its marketing implications. European Journal of marketing. Vol. 18(4), pp. 36-44.

Heskett JL, Sasser WE, Schlesinger LA, (1997). The Service Profit Chain: How Leading Companies Link Profit and Grwoth to Loyalty Satisfaction, and Value. New York: The Free Press.

Holm, M.G., (2000a). Service management in housing refurbishment: a theoretical approach. Construction Management and Economics, 18(5), pp.525-33.

Holm, M.G., (2000b). Service quality and product quality in housing refurbishment. International Journal of Quality Management, 17(4-5), pp.527-40.

Hoonakkera P, Carayona P, Loushine T. (2010). Barriers and benefits of quality management in the construction industry: An empirical study. Total Quality Management. Vol. 21, No. 9, 953 - 969.

Hoxley, M., (1994). Assessment of building surveying service quality: process or outcome? RICS research series paper, $1(8)$.

Hoxley, M., (2000). Measuring UK construction professional service quality: the what, how, when and who. International Journal of Quality and Reliability Management, 17(4/5), pp.511-26.

Kotler, Philip. (2003). Marketing Management. 11st edition. Prentice Hall, New Jersey.

Lai AW, Pang, PS. (2010). Measuring performance for building maintenance providers. Journal of construction engineering and management, 136(8), pp.864-76.

Leonnard. (2018a). Perceived Service Quality, Perceived Value for Money, Satisfaction and Repurchase Intention: An Evaluation on Private Univerisity Services. International Journal of Commerce and Finance. Vol 4. Issue 1, pp. 40-51.

Leonnard. (2018b). Performance of SERVQUAL to Measure Service Quality in Private University. Journal on Effciency and Responsibility in Education and Science. Vol. 11. No.1, pp. 16-21.

Leonnard., Daryanto, H. K., Sukandar, D., Yusuf, E. Z. (2013). The Loyalty Model of Private University Student, Study Case: Stikom London School of Public Relation. International Journal of Information Technology and Business Management. Vol. 20(1), pp. 91-100.

Leonnard, Daryanto, H. K., Sukandar, D., Yusuf, E. Z. (2015). The Loyalty Model of Private University Student. International Research Journal of Business Studies, 7(1).

Leonnard, Susanti, Y. F. (2019). The Advocacy Model of Indonesian Chinese Students, the Affluent Market. International Journal of Instruction, 12(1).

Leonnard., Susilowati, E. (2018). Electronic Word of Mouth (E-WOM) of Transportation Application Consumers in Indonesia: Which Factors That Are Matter. Esensi: Jurnal Bisnis dan Manajemen. Vol. 8 (1), pp. $79-88$.

Li, X, Petrick JF. (2010). Towards and integrative model of loyalty formation: The role of quality and value. Leisure Sciences. Vol 32(3), pp. 201-221.

Loushine, T.W., Hoonakker, P.L.T., Carayon, P., Smith, M.J. (2006). Quality and safety management in construction industry. Total Quality Management and Business Excellence, 17(9), 1771-1212. 
Nelson, S.L. and Nelson, T.R., (1995). RESERV: an instrument for measuring real estate brokerage service quality. Journal of Real Estate Research, 10(1), pp.99-113.

Oliver, R. L. (1997). Satisfaction: A Behavioral Perspective on The Cunsumer. New York: McGraw-Hill, Inc. Omonori A, Lawal A. (2014). Understanding Customers' Satisfaction in Construction Industry in Nigeria. Journal of Economics and Sustainable Development, Vol.5, No.25.

Parasuraman, A., Berry, Leonard L, and Zeithaml, Valarie A. (1985). A Conceptual Model of Service Quality and Its Implications for Future Research. Journal of Marketing, Vol;. 49 (Fall), pp. 41-50.

Parasuraman, A., Berry, Leonard L, and Zeithaml, Valarie A. (1988). SERVQUAL: AMultiple-Item Scale for Measuring Consumer Perceptions of Service Quality. Journal of Retailing, Vol;. 64 (Spring), pp. $12-40$.

Parasuraman, A., Berry, Leonard L, and Zeithaml, Valarie A. (1991). Refinement and Reassessment of The SERVQUAL Scale. Journal of Retailing, Vol;. 67 No. 4 (Winter), pp. 420-450.

Parasuraman, A., Berry, Leonard L, and Zeithaml, Valarie A. (1994). Reassessment of Expectations as a Comparison Standar in Measurung Service Quality: Implications for Future Research. Journal of Marketing, Vol;. 58 (January), pp. 111-124.

PP Properti. 2020. Laporan Tahunan PT PP Properti 2019. Diakses melalui: https://pp-properti.com/wpcontent/uploads/2020/03/ANNUAL-REPORT-PPRO-2019.pdf

Rust, RT, Oliver RL. (1993). Service quality: New directions in theory and practice. Sage Publications.

Samson, D. and Parker, R., (1994). Service quality: the gap in the Australian consulting engineering industry. International Journal of Quality and Reliability Management, 11(7), pp.60-76.

Siu, G.K.W., Bridge, A, Skitmore, M., (2001). Assessing the service quality of building maintenance providers: mechanical and engineering services. Construction Management and Economics, 19(7), pp.719-26.

Sunindijo RY, Hadikusumo BHW, Phangchunun T. (2014). Modelling service quality in the construction industry. International Journal of Business Performance Management, 15(3), 262-276.

Zeithaml, VA. 1988. Consumer perceptions of price, quality, and value: a means-end model and synthesis of evidence. The Journal of Marketing. pp. 2-22. 